\title{
Current Aspect of Bisphenol A Toxicology and Its Health Effects
}

\section{Tanaporn Khamphaya ${ }^{1}$, Phisit Pouyfung ${ }^{1}$, Saruda Kuraeiad ${ }^{2}$, Udomratana Vattanasit ${ }^{3}$ and Supabhorn Yimthiang,}

\author{
${ }^{I}$ Division of Occupational Health and Safety, School of Public Health, Walailak University, \\ Nakhon Si Thammarat 80160, Thailand \\ ${ }^{2}$ Division of Medical Technology, School of Allied Health Sciences, Walailak University, \\ Nakhon Si Thammarat 80160, Thailand \\ ${ }^{3}$ Division of Environmental Health, School of Public Health, Walailak University, \\ Nakhon Si Thammarat 80160, Thailand
}

('Corresponding author's e-mail: ksupapor@mail.wu.ac.th)

Received: 5 December 2020, Revised: 27 May 2021, Accepted: 31 May 2021

\begin{abstract}
Bisphenol A (BPA) is a synthetic and dangerous chemical that is released extensively into the environment. BPA is utilized to synthesize polycarbonate plastics for an assortment of basic items such as electronic gadgets, housewares and apparatuses, water pipes, food packaging and containers. Because of the widespread use of BPA products, people are easily exposed to BPA from using these products in their daily life, especially BPA-contaminated food. BPA intake is found in Oceania, Asia, Europe, and North America in both children and adults. Ingestion is a significant route of BPA exposure. The mechanisms of BPA toxicity involve oxidative stress production, genetic and epigenetic dysregulation, nuclear receptor dysfunction, insulin resistance, and adipose tissue inflammation. Exposure to BPA has many health effects, which include altered neurogenesis and reproductive toxicity. Recently, BPA has also been associated with non-communicable diseases, including cardiovascular disease, cancer, lipid disorder, and diabetes. Toxicological data could provide insights that might be useful for promoting awareness to BPA toxicity and preventing BPA-associated diseases. Herein, this review aims to summarize the current knowledge on the toxicological profiles and health effects of BPA, with emphasis on the mechanisms of its toxicity.
\end{abstract}

Keywords: Bisphenol A, Health effects, Toxicity mechanisms, Toxicokinetics

\section{Introduction}

2,2-Bis (4-hydroxyphenyl) propane (BPA) is an environmental toxicant that is present in large quantities in industrially synthesized compounds. It was first synthesized by AP Dianin in 1891. Approximately $70 \%$ of BPA is produced to synthesize polycarbonate plastics for an assortment of basic items (such as optical media, car, electronic gadgets and compact/digital versatile disc circles, hardware, housewares and apparatuses, water pipes, food packaging and containers, toys, areolas, medicinal gear, and dental items, etc.) [1,2]. Moreover, BPA is a basic part of the epoxy pitches that cover the internal surface of food and drink metallic cans, which shield the metal from erosion [3]. Lacquer degradation might be a significant source of the BPA released in food [4]. BPA migration from canned food containers occurs when the containers are heated for sterilization [5]. Moreover, a high BPA level is found in canned food with a high fat content owing to the high lipid solubility of BPA [6]. Interestingly, BPA is also employed to produce various products, including photoactive dyes in the thermal paper that is used in sales receipts, books, faxes, and labels. It is also used to create handouts, tickets, mailing envelopes, newspapers, kitchen rolls, and bathroom tissue [7]. People have a high risk of exposure to BPA from using these products in their daily life.

BPA intake occurs all around the world in both children and adults [8,9]. BPA has many health effects, including carcinogenesis, neurogenesis, immunotoxicity, reproductive toxicity, and testicular toxicity [10]. The 2013 - 2014 national health and nutrition examination survey (NHANES III) showed that a high concentration of BPA $(1.24 \mu \mathrm{g} / \mathrm{L})$ was found in the urine of $95.7 \%$ of the U.S. population [11]. The highest concentration was found in children, followed by adolescents and then adults $[11,12]$. 
However, although toxicological data regarding BPA have been reported, there has been no literature review of the health effects and toxicity mechanism of BPA. Therefore, this article aims to summarize the current knowledge on the toxicological profiles and health effects of BPA, with emphasis on the mechanisms of its toxicity.

\section{Environment and food contamination}

The environmental accumulation of BPA in the different regions of the world can lead to adverse effects on human health, crop plants, and wildlife through the food chain cycle, where humans can be regarded as the top consumers [13]. Moreover, the United States Environmental Protection Agency (U.S. EPA) reported that soil and rivers are contaminated with 450,000 $\mathrm{kg}$ of BPA every year owing to industrial manufacturing processes; $\mathrm{BPA}$ is found in plastic industry wastewater, wastewater treatment plants, transport, landfills, and BPA-containing products, and also produced via plastic degradation $[14,15]$. BPA can be dumped into the environment from kraft pulp and printing paper, which are the primary sources of BPA contamination. Moreover, BPA was found to migrate from BPA-based products and industrial materials into the environment through wastewater [16-18].

Furthermore, BPA at concentrations ranging from 4 to $1730 \mu \mathrm{g} / \mathrm{L}$ was leached from plastics such as polyvinyl chloride (PVC), which are used in drainage, water, and sprinkler systems in many houses and buildings [19]. In 2007, another study reported that the environmental concentration of BPA was as high as $25 \mu \mathrm{g} / \mathrm{L}$, which significantly exceeded the lowest effective concentrations in aquatic organisms and thus could harm the aquatic environment [20]. This is why it is not surprising that there is a high level of BPA found in aquatic food, both in coastal water and freshwater. For example, BPA was found in green mussel (Perna viridis), an aquatic seafood collected from the eastern coast of Thailand, where there is a major industrial and wastewater zone. Therefore, seafood originating from areas near major industrial and wastewater zones may be an important source of BPA [21]. Packaging and storage containers of food and beverage are other main sources of BPA, as BPA from the polymeric coating of food cans or plastic bottles can leach into the contained food and drink [22].

\section{BPA toxicological profiles}

The toxicological profile of BPA has been elucidated in 2008 by the U.S. Food and Drug Administration (FDA). According to the FDA report, the highest dose of BPA that leads to no detectable adverse effect, also known as the no-observed-adverse-effect level (NOAEL), is $5 \mathrm{mg} / \mathrm{kg}$ body weight/day [23]. This value is minimally 500-fold higher than the estimated daily intake concentration of BPA by humans [24]. Moreover, the European Food Safety Authority has published in 2015 a comprehensive evaluation of BPA exposure and toxicity, and the tolerable daily intake for BPA is 4 $\mu \mathrm{g} / \mathrm{kg}$ body weight/day [23]. Ingestion is the main route of human exposure to BPA, and the estimated global daily intakes of BPA by adults, children, pregnant women, and infants are 30.8, 60.1, 42.0 and $92.7 \mathrm{ng} / \mathrm{kg}$ body weight/day, respectively [25]. A possible reason for the higher daily intake of BPA in infants was than in children and adults may be the high level of BPA contamination in product that have contact with baby food, particularly in baby bottles. Previous studies showed that BPA leached rapidly from baby bottles when the water temperatures is increased to over $80{ }^{\circ} \mathrm{C}$ [7]. In addition, when the temperature is increased to $100{ }^{\circ} \mathrm{C}$, BPA can be released from epoxy resins in coated cans [26]. Therefore, high-temperature conditions should be a concern with respect to BPA exposure, especially in children and pregnant women because exposure to BPA at doses below the NOAEL is still dangerous during the developmental period. The global evaluated risks of daily BPA exposure for children and pregnant women are 2 and 1.4 times higher than that for adults, respectively [27]. Biomarkers for BPA exposure in children and pregnant women may be needed.

Ingestion is a major route of BPA exposure, but not the only way. Populations living near BPAcontaminated areas, such as e-waste recycling sites, were found to have 3-5 times higher BPA levels in their urine than the normal population [28]. Moreover, BPA can also be absorbed through the skin, especially when using printed thermal paper [29], or via inhalation of household dust from BPA synthetic polymers [30]. Nevertheless, it is believed that the exposure of the general population to BPA via dust inhalation is considerably lower than that via food consumption [31]. Furthermore, in vivo studies have indicated the ability of BPA to penetrate the blood-brain barrier and cross the placenta due to its lipophilic nature [32,33]. 
$\mathbf{A}$<smiles>CC(C)(c1ccc(O)cc1)c1ccc(O)cc1</smiles>

C<smiles>CC(C)(c1ccc(O)cc1)c1ccc(O)c(O)c1</smiles>

$\mathbf{E}$

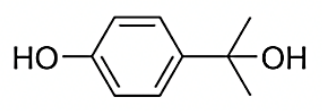

B<smiles>CC(CO)(c1ccc(O)cc1)c1ccc(O)cc1</smiles>

D<smiles>C=C(C)c1ccc(O)cc1</smiles>

F

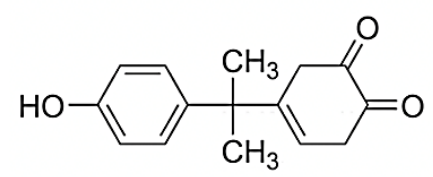

Figure 1 Chemical structures of BPA and its metabolites. A) Bisphenol A (BPA; 2,2-bis(4hydroxyphenyl) propane), B) 2,2-Bis(4-hydroxyphenyl) propanol, C) 3-Hydroxybisphenol A (3-OHBPA), D) 4-Isopropenylphenol (IPP), E) Hydroxycumyl alcohol (HCA) and F) 3,4-quinone BPA (BPAquinone).

BPA, $\left(\mathrm{CH}_{3}\right)_{2} \mathrm{C}\left(\mathrm{C}_{6} \mathrm{H}_{4} \mathrm{OH}\right)_{2}$ is an organic synthetic compound (Figure 1A) that is metabolized by microsomal cytochrome P450 monooxygenases (CYPs) (mainly CYP3A4, CYP3A5 and CYP2D6*1) to various products including 2,2-bis(4-hydroxyphenyl) propanol (Figure 1B), 3-hydroxybisphenol A (3OH-BPA) (Figure 1C), 4-isopropylphenol (IPP) (Figure 1D), hydroxycumyl alcohol (HCA) (Figure 1E), and 3,4-quinone BPA (BPA-quinone) (Figure 1F) [34,35]. The reactive metabolite, BPA-quinone, binds to genetic material and forms DNA adducts, and is thus responsible for the genotoxicity of BPA. Moreover, BPA-quinone participates in redox reactions, resulting in oxidative stress [36]. Interestingly, most BPA metabolites exert stronger estrogen activity than the parent compounds, such as HCA, which showed stronger estrogen receptor (ER)-binding activity than BPA [34,37,38]. In phase II biotransformation, BPA and its metabolites are conjugated with glucuronide and sulphate by the uridine diphosphate-glucuronosyltransferase 2B15 and estrogen sulfotransferase, respectively [39,40]. It was also reported that BPA and its metabolites are conjugated with glutathione and other thiols characterized by BPA glutathione conjugate, glutathionyl-phenol, and glutathionyl 4-isopropylphenol in rat liver fractions [35]. Species differences in the biotransformation of BPA have been reported. Bisphenol A glucuronide has a high enterohepatic circulation in rats, resulting in a slow rate of excretion through bile and feces, but it undergoes first-pass-metabolism in humans owing the absence of enterohepatic circulation and is rapidly eliminated by the kidney via urine [41,42]. However, there is no first pass effect in the case of inhalation or dermal absorption of unconjugated BPA [43]. The half-life of BPA after oral intake in humans is approximately 6 to $43 \mathrm{~h}$. The other minor metabolites of BPA are only formed the glucuronidation pathway is saturated. BPA glucuronide is the major metabolite present, and it serves as a biomarker of human BPA exposure due to its expected presence at high concentrations and the lack of background caused by contamination. Even though BPA is rapidly metabolized, many studies have identified the adverse health effects associated with BPA exposure in both humans and animal models [44].

\section{Mechanisms of BPA toxicity}

\section{Nuclear receptor regulation}

BPA is a weak estrogen that shows less affinity to estrogen receptors than to $17 \beta$-estradiol (E2), which is the most effective estrogen [45]. However, ER localization at the nuclear membrane can induce rapid extranuclear response (a nongenomic mechanism within seconds to minutes) by estrogen and other mimic ligands binding to the ERs. BPA exerts estrogen activity by stimulating extracellular signals through kinase/mitogen-activated protein kinase and phosphatidyl-inositol-3-kinase phosphorylation [46]. BPA can trigger $\mathrm{Ca}^{2+}$ release from intracellular stores through ER $\alpha$ extranuclear mechanisms, leading to changes in cell transportability and signaling processes [47]. Moreover, BPA bound to ERs may cause common chronic diseases such as hypertension, atherosclerosis, liver dysfunction, diabetes, and obesity [48-50]. BPA has been associated with numerous nuclear receptors, such as androgen receptors (thereby 
interfering with the male reproductive system), androgen-related receptors gamma (thus affecting the development of mammalian brain), constitutive androstane receptors, pregnane $\mathrm{X}$ receptors and peroxisome proliferator-activated receptors $(P P A R \gamma)$ (thus inducing the onset of obesity and metabolic syndromes) [51]. Furthermore, BPA increases a mitogenic factor, apelin, which results in stimulating ovarian cancer cell progression through a PPAR $\gamma$-dependent mechanism [52].

\section{Epigenetic regulation}

BPA exerts teratogenicity through epigenetic regulation both in vitro and in vivo. A study in human embryonic stem cells found that BPA affects fetal neuronal system development by significantly decreasing DNA methylation and DNA methyltransferase expression [33]. Moreover, BPA inhibits testicular ten-eleven translocation proteins, resulting in decreased DNA methylation and increased DNA hypermethylation in Gobiocypris rarus testes [53]. Furthermore, prenatal exposure to BPA can cause changes in DNA methylation and histone acetylation which may result in an increased susceptibility to prostate carcinogenesis through the epigenetic mechanisms [54].

\section{Genetic regulation of lipid and glucose homeostasis}

BPA is an endocrine disruptor; it suppresses adiponectin function, leading to insulin resistance and increased susceptibility to obesity-associated diseases [55]. The stimulatory effects of BPA cause hypercholesterolemia. It has been reported that BPA enhances hepatic cholesterol biosynthesis via increased expression of sterol regulatory element-binding protein 2, which is a key regulator in cholesterol biosynthesis. BPA also promotes cholesterol absorption in the intestinal cells [50,56]. Recent epidemiological and animal studies have suggested that BPA is involved in the development of obesity, type 2 diabetes, and cardiovascular diseases. Another study reported that female cashiers had increased urinary levels of BPA, which is associated with insulin levels, due to receipt handling [57]. The liver is a target organ of BPA-regulated insulin action. In vivo studies indicated that BPA impairs insulin sensitivity and inhibits insulin signaling in the hepatocytes of BPA-treated mice [58]. Moreover, a study in cultured human liver cancer cells supports a direct effect of BPA in hepatocytes via the increased expression of inflammatory genes and enhanced glucose production and steatosis. BPA can also cause pancreatic $\beta$-cell toxicity, which results in dysfunctions of insulin catabolism, secretion, and action $[59,60]$. Therefore, BPA can be considered a risk factor for the development of major public health problems, including obesity, type 2 diabetes, and enhanced atherosclerosis.

\section{Oxidative stress}

BPA causes reactive oxygen species (ROS) accumulation-induced damage to the mitochondria, endoplasmic reticulum, and most endoplasmic reticulum stress-related proteins in vitro and in vivo models. ROS accumulation regulates the PERK/EIF2 $\alpha /$ chop pathway, which is an important factor in BPA-induced reproductive toxicity [61]. In an animal study, BPA significantly decreased the level of antioxidant enzymes, including glutathione, superoxide dismutase, glutathione peroxidase, and catalase, while significantly enhancing the level of ROS; in particular, BPA increased the levels of lipid peroxidation markers, such as malondialdehyde (MDA) and nitric oxide (NO) [62]. In human studies enrolling individuals from the areas surrounding e-waste sites, BPA levels in urine were significantly correlated with 8-hydroxy-2'-deoxyguanosine levels in urine $(P<0.001)$ [28]. Current data suggest that BPA exposure increases oxidative stress and significantly decreases antioxidant system activity [53].

\section{BPA toxicity to the nervous and reproductive systems}

Even at levels lower than the NOAEL ( $5 \mathrm{mg} / \mathrm{kg}$ body weight/day), BPA can cause changes in brain biochemical signaling in children during the development stage. BPA affects many stages of brain maturation from the embryonic to the adolescent stages, leading to learning and memory impairment even after BPA exposure has ended [63-65]. Recent reports showed that BPA alters the proliferation and differentiation of neurogenesis [66]. Furthermore, BPA exposure interrupts brain development, causing learning and memory impairment by suppressing the expressions of ER- $\beta$ and glutamate receptors as well as $N$-methyl- $D$-aspartate receptor subunits in the hippocampus during the development stage [67].

BPA acts as a weak estrogenic agonist when estradiol is absent, and as an endocrine disruptor if estradiol is present [68]. Estradiol is a crucial factor in spine density in the rat hippocampus and cerebral cortex, which are related to cognitive function [69]. Several studies have shown changes in neuronal density related to BPA. However, there are only few studies that focus on brain function after the changes in neuronal density. The interaction of BPA with the endocrine system seems to lead to gender-specific changes [70]. BPA is involved with metabolism of androgens, resulting in different outcomes including 
reduced semen quality and reduced oocyte yield. The testicular toxicity of BPA may be mediated via alterations in N-cadherin, vimentin and follicle-stimulating hormone receptor (FSH-R) expression, thus disturbing normal spermatogenesis [71]. BPA also reduces testosterone synthesis, induces cell death, impairs the growth and mitochondria membrane potential of Leydig cells in a dose-dependent manner [72]. In addition, BPA can interact with estrogen nuclear receptors (transcription factor-dependent nuclear localization) and inhibit the expression of genes involved in the mitotic cell cycle. It raises the possibility that fetal BPA exposure may limit the expansion of the primordial germ cell population $[73,74]$.

\section{BPA health effects}

The association between human exposure to BPA and diseases have been reported in many academic publications. Recently, it has been reported that BPA as an endocrine disruptor may increase susceptibility to non-communicable diseases, such as obesity, cardiovascular disease and type 2 diabetes. Studies have shown that BPA concentration in urine is positively correlated cardiovascular disease and type 2 diabetes [75]. The European Union has 42,400 cases of childhood obesity, and there is a 20.0 to $69.0 \%$ probability of prenatal BPA exposure. The associated lifetime costs are approximately $£ 1.54$ billion in the EU [76]. However, there is no data on health costs related to BPA-induced obesity in other regions. Thus, BPA is known as an obesogen. Increased body weight and/or body mass index during BPA exposure were observed in all stages of life development from prenatal to childhood, and might be related to the proteins involved in appetite [66]. Recent data have shown that the obesity-related mechanisms of BPA include lipid and glucose dysregulation as well as adipose tissue inflammation [76]. Increased BPA exposure is also correlated with other adverse health outcomes across human populations including increased sex hormone concentrations, decreased spermatozoa quality, changes in child behavior and performance, and increased abortion, along with other metabolic and reproductive dysfunctions [4,44]. Further evidence from in vivo and in vitro studies suggest that the cancer-promoting properties of BPA at doses below the reference doses cause an increased incidence of breast cancer [15]. Animal studies revealed that BPA affected the hippocampus by reducing synaptogenesis and neurogenesis in postnatal rats and young adult mice [77]. BPA has also been found to cause hyperactiveness in rats, affect cognitive function, alter adult spontaneous behaviors, decrease the proliferation of neural progenitor cells, and cause cell toxicity during brain development $[32,78]$. In vivo studies have also shown that BPA affects locomotor activity in various aspects of memory, causes autism, and cause aggressive behaviors in the progeny of mothers with high BPA levels [78]. Moreover, some reports showed that BPA exposure increases the risk of meningioma and brain cancer. Meningioma patients are likely to have approximately 1.4 to 1.6 times higher urinary BPA levels than healthy volunteers (individuals without meningioma) [79].

\section{Conclusions}

BPA is an environmental toxicant resulting in many adverse health effects. However, it is also an essential material used in food containers and various other types of products used daily. The mechanism of BPA toxicity is complicated, involving many physiological systems including the endocrine, neuronal, and reproductive systems. The adverse health effects of BPA have been reported, such as $i$ ) hormone imbalance resulting in common non-communicable diseases (obesity, type 2 diabetes, cardiovascular disease, and metabolic disorder) and ii) interference with brain development (learning and memory impairment, locomotion disability, and behavioral problems). Pregnant women and children are especially vulnerable to BPA exposure, which can result in diseases development later in life. This review provides information on BPA-associated diseases to assist in the future development of biomarkers and public health intervention measures.

However, there is a limitation in this review. By design, this is a narrative review. The primary sources of data were primary research articles and review articles between 1995 - 2021. The review included all relevant articles for each topic and it is up to date (2021). A systematic review of this topic could also be performed to support or discredit the findings presented herein. 


\section{References}

[1] YQ Huang, CK Wong, JS Zheng, H Bouwman, R Barra, B Wahlström, L Neretin and MH Wong. Bisphenol A (BPA) in China: A review of sources, environmental levels, and potential human health impacts. Environ. Int. 2012; 42, 91-9.

[2] A Abraham and P Chakraborty. A review on sources and health impacts of bisphenol A. Rev. Environ. Health 2020; 35, 201-10.

[3] S Eladak, T Grisin, D Moison, MJ Guerquin, T N'Tumba-Byn, S Pozzi-Gaudin, A Benachi, G Livera, V Rouiller-Fabre and R Habert. A new chapter in the bisphenol A story: Bisphenol S and bisphenol F are not safe alternatives to this compound. Fertil. Steril. 2015; 103, 11-21.

[4] LN Vandenberg, R Hauser, M Marcus, N Olea and WV Welshons. Human exposure to bisphenol A (BPA). Reprod. Toxicol. 2007; 24, 139-77.

[5] J Corrales, LA Kristofco, WB Steele, BS Yates, CS Breed, ES Williams and BW Brooks. Global Assessment of Bisphenol A in the Environment: Review and analysis of its occurrence and bioaccumulation. Dose-Response 2015; 13, 1-29.

[6] T Geens, TZ Apelbaum, L Goeyens, H Neels and A Covaci. Intake of bisphenol A from canned beverages and foods on the Belgian market. Food Addit. Contam. A Chem. Anal. Control. Expo. Risk Assess. 2010; 27, 1627-37.

[7] SH Nam, YM Seo and MG Kim. Bisphenol A migration from polycarbonate baby bottle with repeated use. Chemosphere 2010; 79, 949-52.

[8] RP Huang, ZH Liu, H Yin, Z Dang, PX Wu, NW Zhu and Z Lin. Bisphenol A concentrations in human urine, human intakes across six continents, and annual trends of average intakes in adult and child populations worldwide: A thorough literature review. Sci. Total Environ. 2018; 626, 971-81.

[9] H Jin, J Xie, L Mao, M Zhao, X Bai, J Wen, T Shen and P Wu. Bisphenol analogue concentrations in human breast milk and their associations with postnatal infant growth. Environ. Pollut. 2020; 259, 113779.

[10] M Murata and JH Kang. Bisphenol A (BPA) and cell signaling pathways. Biotechnol. Adv. 2018; 36, 311-27.

[11] HJ Lehmler, B Liu, M Gadogbe and W Bao. Exposure to bisphenol A, bisphenol F, and bisphenol S in U.S. adults and children: The National Health and Nutrition Examination Survey 2013 - 2014. ACS Omega 2018; 3, 6523-32.

[12] AM Calafat, X Ye, LY Wong, JA Reidy and LL Needham. Exposure of the U.S. population to bisphenol A and 4-tertiary-octylphenol: 2003 - 2004. Environ. Health Perspect. 2008; 116, 39-44.

[13] RC Thompson, CJ Moore, FS vom Saal and SH Swan. Plastics, the environment and human health: Current consensus and future trends. Philos. Trans. R Soc. Lond. B Biol. Sci. 2009; 364, 2153-66.

[14] DD Seachrist, KW Bonk, SM Ho, GS Prins, AM Soto and RA Keri. A review of the carcinogenic potential of bisphenol A. Reprod. Toxicol. 2016; 59, 167-82.

[15] Z Wang, H Liu and S Liu. Low-dose bisphenol A exposure: A seemingly instigating carcinogenic effect on breast cancer. Adv. Sci. (Weinh) 2017; 4, 1600248.

[16] T Yamamoto and A Yasuhara. Quantities of bisphenol a leached from plastic waste samples. Chemosphere 1999; 38, 2569-76.

[17] M Fuerhacker. Bisphenol A emission factors from industrial sources and elimination rates in a sewage treatment plant. Water Sci. Technol. 2003; 47, 117-22.

[18] A Rigol, A Latorre, S Lacorte and D Barcelo. Bioluminescence inhibition assays for toxicity screening of wood extractives and biocides in paper mill process waters. Environ. Toxicol. Chem. 2004; 23, 339-47.

[19] T Yamamoto, A Yasuhara, H Shiraishi and O Nakasugi. Bisphenol A in hazardous waste landfill leachates. Chemosphere 2001; 42, 415-8.

[20] DA Crain, M Eriksen, T Iguchi, S Jobling, H Laufer, GA LeBlanc and LJ Guillette Jr. An ecological assessment of bisphenol-A: evidence from comparative biology. Reprod. Toxicol. 2007; 24, 225-39.

[21] Y Ocharoen, C Boonphakdee, T Boonphakdee, AP Shinn and S Moonmangmee. High levels of the endocrine disruptors bisphenol-A and $17 \beta$-estradiol detected in populations of green mussel, Perna viridis, cultured in the Gulf of Thailand. Aquaculture 2018; 497, 348-56.

[22] A Lestido Cardama, R Sendon, J Bustos, MI Santillana, P Paseiro Losada and A Rodriguez Bernaldo de Quiros. GC-MS Screening for the identification of potential migrants present in polymeric coatings of food cans. Polymers (Basel) 2019; 11, 2086.

[23] EFSA Panel on Biological Hazards (BIOHAZ). Request for clarification on the Scientific Opinion on the public health risks related to the maintenance of the cold chain during storage and transport 
of meat (Part 1 and Part 2) European Food Safety Authority. Eur. Food Saf. Authority J. 2015; 13, 3783.

[24] World Health Organization \& Food and Agriculture Organization of the United Nations. Joint FAO/WHO expert meeting to review toxicological and health aspects of bisphenol A: final report, including report of stakeholder meeting on bisphenol A, 1-5 November 2010, Ottawa,Canada. World Health Organization, Geneva, Switzerland, 2011.

[25] RP Huang, ZH Liu, SF Yuan, H Yin, Z Dang and PX Wu. Worldwide human daily intakes of bisphenol A (BPA) estimated from global urinary concentration data (2000-2016) and its risk analysis. Environ. Pollut. 2017; 230, 143-52.

[26] Y Takao, HC Lee, S Kohra and K Arizono. Release of bisphenol A from food can lining upon heating. J. Health Sc. 2002; 48, 331-4.

[27] RP Huang, ZH Liu, SF Yuan, H Yin, Z Dang and PX Wu. Worldwide human daily intakes of bisphenol A (BPA) estimated from global urinary concentration data (2000-2016) and its risk analysis. Environ. Pollut. 2017; 230, 143-52.

[28] T Zhang, J Xue, CZ Gao, RL Qiu, YX Li, X Li, MZ Huang and K Kannan. Urinary concentrations of bisphenols and their association with biomarkers of oxidative stress in people living near e-waste recycling facilities in China. Environ. Sci. Tech. 2016; 50, 4045-53.

[29] MR Bernier and LN Vandenberg. Handling of thermal paper: Implications for dermal exposure to bisphenol A and its alternatives. PLoS One 2017; 12, e0178449.

[30] D Zalko, C Jacques, H Duplan, S Bruel and E Perdu. Viable skin efficiently absorbs and metabolizes bisphenol A. Chemosphere 2011; 82, 424-30.

[31] T Geens, D Aerts, C Berthot, JP Bourguignon, L Goeyens, P Lecomte, G Maghuin-Rogister, AM Pironnet, L Pussemier, ML Scippo, J Van Loco and A Covaci. A review of dietary and non-dietary exposure to bisphenol-A. Food Chem. Toxicol. 2012; 50, 3725-40.

[32] CS Kim, PP Sapienza, IA Ross, W Johnson, HM Luu and JC Hutter. Distribution of bisphenol A in the neuroendocrine organs of female rats. Toxicol. Ind. Health 2004; 20, 41-50.

[33] L Du, W Sun, XM Li, XY Li, W Liu and D Chen. DNA methylation and copy number variation analyses of human embryonic stem cell-derived neuroprogenitors after low-dose decabromodiphenyl ether and/or bisphenol A exposure. Hum. Exp. Toxicol. 2018; 37, 475-85.

[34] S Nakamura, Y Tezuka, A Ushiyama, C Kawashima, Y Kitagawara, K Takahashi, S Ohta and T Mashino. Ipso substitution of bisphenol A catalyzed by microsomal cytochrome P450 and enhancement of estrogenic activity. Toxicol. Lett. 2011; 203, 92-5.

[35] JP Jaeg, E Perdu, L Dolo, L Debrauwer, JP Cravedi and D Zalko. Characterization of new bisphenol a metabolites produced by CD1 mice liver microsomes and S9 fractions. J. Agr. Food Chem. 2004; 52, 4935-42.

[36] A Atkinson and D Roy. In vivo DNA adduct formation by bisphenol A. Environ. Mol. Mutagen. 1995; 26, 60-6.

[37] P Kovacic. How safe is bisphenol A? Fundamentals of toxicity: Metabolism, electron transfer and oxidative stress. Med. Hypotheses 2010; 75, 1-4.

[38] K Okuda, M Takiguchi and S Yoshihara. In vivo estrogenic potential of 4-methyl-2,4-bis(4hydroxyphenyl)pent-1-ene, an active metabolite of bisphenol A, in uterus of ovariectomized rat. Toxicol. Lett. 2010; 197, 7-11.

[39] N Hanioka, H Oka, K Nagaoka, S Ikushiro and S Narimatsu. Effect of UDP-glucuronosyltransferase 2B15 polymorphism on bisphenol A glucuronidation. Arch. Toxicol. 2011; 85, 1373-81.

[40] CL Stowell, KK Barvian, PCM Young, RM Bigsby, DE Verdugo, CR Bertozzi and TS Widlanski. A role for sulfation-desulfation in the uptake of bisphenol a into breast tumor cells. Chem. Biol. 2006; 13, 891-7.

[41] RE Chapin, J Adams, K Boekelheide, LE Gray Jr, SW Hayward, PS Lees, BS McIntyre, KM Portier, TM Schnorr, SG Selevan, JG Vandenbergh and SR Woskie. NTP-CERHR expert panel report on the reproductive and developmental toxicity of bisphenol A. Birth Defects Res. B Dev. Reprod. Toxicol. 2008; 83, 157-395.

[42] T Miyaguchi, H Suemizu, M Shimizu, S Shida, S Nishiyama, R Takano, N Murayama and H Yamazaki. Human urine and plasma concentrations of bisphenol A extrapolated from pharmacokinetics established in in vivo experiments with chimeric mice with humanized liver and semi-physiological pharmacokinetic modeling. Regul. Toxicol. Pharmacol. 2015; 72, 71-6.

[43] MA Martinez, J Rovira, R Prasad Sharma, M Nadal, M Schuhmacher and V Kumar. Comparing dietary and non-dietary source contribution of BPA and DEHP to prenatal exposure: A catalonia (Spain) case study. Environ. Res. 2018; 166, 25-34. 
[44] J Michalowicz. Bisphenol A--sources, toxicity and biotransformation. Environ. Toxicol. Pharmacol. 2014; 37, 738-58.

[45] A Bolli, P Bulzomi, P Galluzzo, F Acconcia and M Marino. Bisphenol A impairs estradiol-induced protective effects against DLD-1 colon cancer cell growth. IUBMB Life 2010; 62, 684-7.

[46] F Acconcia and M Marino. The effects of 17beta-estradiol in cancer are mediated by estrogen receptor signaling at the plasma membrane. Front. Physiol. 2011; 2, 30.

[47] AL Wozniak, NN Bulayeva and CS Watson. Xenoestrogens at picomolar to nanomolar concentrations trigger membrane estrogen receptor-alpha-mediated $\mathrm{Ca} 2+$ fluxes and prolactin release in GH3/B6 pituitary tumor cells. Environ. Health Perspect. 2005; 113, 431-9.

[48] P Alonso-Magdalena, S Morimoto, C Ripoll, E Fuentes and A Nadal. The estrogenic effect of bisphenol A disrupts pancreatic beta-cell function in vivo and induces insulin resistance. Environ. Health Perspect. 2006; 114, 106-12.

[49] A Marmugi, S Ducheix, F Lasserre, A Polizzi, A Paris, N Priymenko, J Bertrand-Michel, T Pineau, $\mathrm{H}$ Guillou, PG Martin and L Mselli-Lakhal. Low doses of bisphenol A induce gene expression related to lipid synthesis and trigger triglyceride accumulation in adult mouse liver. Hepatology 2012; 55, 395-407.

[50] A Marmugi, F Lasserre, D Beuzelin, S Ducheix, L Huc, A Polizzi, M Chetivaux, T Pineau, P Martin, H Guillou and L Mselli-Lakhal. Adverse effects of long-term exposure to bisphenol A during adulthood leading to hyperglycaemia and hypercholesterolemia in mice. Toxicology 2014; 325, 133-43.

[51] F Acconcia, V Pallottini and M Marino. Molecular Mechanisms of Action of BPA. Dose Response 2015; 13, 1-9.

[52] M Hoffmann, E Fiedor and A Ptak. Bisphenol A and its derivatives tetrabromobisphenol A and tetrachlorobisphenol A induce apelin expression and secretion in ovarian cancer cells through a peroxisome proliferator-activated receptor gamma-dependent mechanism. Toxicol. Lett. 2017; 269, $15-22$.

[53] C Yuan, Y Zhang, Y Liu, S Wang and Z Wang. DNA demethylation mediated by down-regulated TETs in the testes of rare minnow Gobiocypris rarus under bisphenol A exposure. Chemosphere 2017; 171, 355-61.

[54] SM Ho, WY Tang, J Belmonte de Frausto and GS Prins. Developmental exposure to estradiol and bisphenol A increases susceptibility to prostate carcinogenesis and epigenetically regulates phosphodiesterase type 4 variant 4. Cancer. Res. 2006; 66, 5624-32.

[55] ER Hugo, TD Brandebourg, JG Woo, J Loftus, JW Alexander and N Ben-Jonathan. Bisphenol A at environmentally relevant doses inhibits adiponectin release from human adipose tissue explants and adipocytes. Environ. Health Perspect. 2008; 116, 1642-7.

[56] D Feng, J Zou, S Zhang, X Li, P Li and M Lu. Bisphenol A promotes cholesterol absorption in Caco-2 cells by up-regulation of NPC1L1 expression. Lipids Health Dis. 2017; 16, 2.

[57] I Lee, S Kim, KT Kim, S Kim, S Park, H Lee, Y Jeong, JE Lim, HB Moon and K Choi. Bisphenol A exposure through receipt handling and its association with insulin resistance among female cashiers. Environ. Int. 2018; 117, 268-75.

[58] TM Batista, P Alonso-Magdalena, E Vieira, ME Amaral, CR Cederroth, S Nef, I Quesada, EM Carneiro and A Nadal. Short-term treatment with bisphenol-A leads to metabolic abnormalities in adult male mice. PLoS One 2012; 7, e33814.

[59] C Fang, B Ning, AB Waqar, M Niimi, S Li, K Satoh, M Shiomi, T Ye, S Dong and J Fan. Bisphenol A exposure induces metabolic disorders and enhances atherosclerosis in hyperlipidemic rabbits. J. Appl. Toxicol. 2015; 35, 1058-70.

[60] B Le Magueresse-Battistoni, L Multigner, C Beausoleil and C Rousselle. Effects of bisphenol A on metabolism and evidences of a mode of action mediated through endocrine disruption. Mol. Cell. Endocrinol. 2018; 475, 74-91.

[61] L Yin, Y Dai, Z Cui, X Jiang, W Liu, F Han, A Lin, J Cao and J Liu. The regulation of cellular apoptosis by the ROS-triggered PERK/EIF2alpha/chop pathway plays a vital role in bisphenol Ainduced male reproductive toxicity. Toxicol. Appl. Pharmacol. 2017; 314, 98-108.

[62] T Ozaydin, Y Oznurlu, E Sur, I Celik, D Uluisik and MO Dayan. Effects of bisphenol A on antioxidant system and lipid profile in rats. Biotech. Histochem. 2018; 93, 231-8.

[63] P Grandjean and PJ Landrigan. Developmental neurotoxicity of industrial chemicals. Lancet 2006; 368, 2167-78.

[64] SA Johnson, AB Javurek, MS Painter, MR Ellersieck, TH Welsh Jr, L Camacho, SM Lewis, MM Vanlandingham, SA Ferguson and CS Rosenfeld. Effects of developmental exposure to bisphenol A 
on spatial navigational learning and memory in rats: A CLARITY-BPA study. Horm. Behav. 2016; 80, 139-48.

[65] D Kumar and MK Thakur. Perinatal exposure to bisphenol-A impairs spatial memory through upregulation of neurexin 1 and neuroligin3 expression in male mouse brain. PLoS One 2014; 9 , e110482.

[66] M Desai, MG Ferrini, G Han, JK Jellyman and MG Ross. In vivo maternal and in vitro BPA exposure effects on hypothalamic neurogenesis and appetite regulators. Environ. Res. 2018; 164, 45-52.

[67] XH Xu, J Zhang, YM Wang, P Ye and QQ Luo. Perinatal exposure to bisphenol-A impairs learning-memory by concomitant down-regulation of N-methyl-D-aspartate receptors of hippocampus in male offspring mice. Horm. Behav. 2010; 58, 326-33.

[68] X Xu, T Gu and Q Shen. Different effects of bisphenol-A on memory behavior and synaptic modification in intact and estrogen-deprived female mice. J. Neurochem. 2015; 132, 572-82.

[69] CS Woolley. Estrogen-mediated structural and functional synaptic plasticity in the female rat hippocampus. Horm. Behav. 1998; 34, 140-8.

[70] L Caporossi and B Papaleo. Exposure to bisphenol A and gender differences: from rodents to humans evidences and hypothesis about the health effects. J. Xenobiot. 2015; 5, 5264.

[71] W Chen, P Duan, S Tang, WT Huang, C Quan, SQ Qi and KD Yang. [Effects of bisphenol A on the expression of N-cadherin, Vimentin and FSHR in rat Sertoli cells]. Zhonghua Lao Dong Wei Sheng Zhi Ye Bing Za Zhi 2017; 35, 101-5.

[72] GD Goncalves, SC Semprebon, BI Biazi, MS Mantovani and GSA Fernandes. Bisphenol A reduces testosterone production in TM3 Leydig cells independently of its effects on cell death and mitochondrial membrane potential. Reprod. Toxicol. 2018; 76, 26-34.

[73] D Caserta, N Di Segni, M Mallozzi, V Giovanale, A Mantovani, R Marci, M Moscarini. Bisphenol A and the female reproductive tract: An overview of recent laboratory evidence and epidemiological studies. Reprod. Biol. Endocrinol. 2014; 12, 37.

[74] C Lawson, M Gieske, B Murdoch, P Ye, Y Li, T Hassold and PA Hunt. Gene expression in the fetal mouse ovary is altered by exposure to low doses of bisphenol A. Biol. Reprod. 2011; 84, 79-86.

[75] IA Lang, TS Galloway, A Scarlett, WE Henley, M Depledge, RB Wallace and D Melzer. Association of urinary bisphenol A concentration with medical disorders and laboratory abnormalities in adults. JAMA 2008; 300, 1303-10.

[76] J Legler, T Fletcher, E Govarts, M Porta, B Blumberg, JJ Heindel and L Trasande. Obesity, diabetes, and associated costs of exposure to endocrine-disrupting chemicals in the European Union. J. Clin. Endocrinol. Metab. 2015; 100, 1278-88.

[77] YJ Jang, HR Park, TH Kim, WJ Yang, JJ Lee, SY Choi, SB Oh, E Lee, JH Park, HP Kim, HS Kim and $\mathrm{J}$ Lee. High dose bisphenol A impairs hippocampal neurogenesis in female mice across generations. Toxicology 2012; 296, 73-82.

[78] M Preciados, C Yoo and D Roy. Estrogenic endocrine disrupting chemicals influencing NRF1 regulated gene networks in the development of complex human brain diseases. Int. J. Mol. Sci. $2016 ; 17,2086$.

[79] B Duan, X Hu, H Zhao, J Qin and J Luo. The relationship between urinary bisphenol A levels and meningioma in Chinese adults. Int. J. Clin. Oncol. 2013; 18, 492-7. 